\title{
Pengaruh warna lampu light emitting diode dalam air terhadap hasil tangkapan ikan Teri (Stolephorus commersonii) dengan bagan
}

\author{
The effect of light emitting diode color in water on Anchovy catch (Stolephorus commersonii) \\ on lift net
}

\author{
Christianti T. AMos*, Revols D.Ch. PAMikiran dan PATRice N. I. KALANGI \\ Program Studi Pemanfaatan Sumberdaya Perikanan, Fakultas Perikanan dan Ilmu Kelautan, \\ Universitas Sam Ratulangi, Manado, 95115
}

\begin{abstract}
Lift nets is one of the fishing gear which operate at the night. This fishing gear are using light as a aids to attract fish into the fishing area. Research on the use of LED lights in water on lift nets is carried out in Tateli Weru Waters, with the aim to see how the effect of using different color underwater LED lights on anchovy catches (Stolephorus commersonii), and knowing the amount of anchovy (Stolephorus commersonii) catch on lift net using the experimental method, where data is analyzed using Completely Randomized Block Design (RCBD), and continued by Least Significant Difference test (LSD). Trial of anchovy fishing (Stolephorus commersonii) was conducted in December 2018 for 10 days by operating boat lift nets using green, blue and green-blue LED lights. The results showed that the use of LED light colors in blue water had a very significant effect on the amount of anchovy catch (Stolephorus comersonii) compared to to the color of LED lights in green-blue and green water. Whereas the use of LED light colors in blue-green water with green is not statistically significantly different from the amount of anchovy caught (Stolephorus comersonii).
\end{abstract}

Keywords: Boat lift net; LED light color; Anchovy (Stolephorus commersonii); Tateli Weru

\begin{abstract}
ABSTRAK
Bagan merupakan salah satu alat penangkapan ikan yang dioperasikan pada malam hari. Alat tangkap ini menggunakan cahaya lampu sebagai alat bantu untuk menarik ikan masuk ke dalam area penangkapan. Penelitian mengenai penggunaan lampu LED dalam air pada bagan dilakukan di Perairan Tateli Weru, dengan tujuan untuk melihat bagaimana pengaruh penggunaan lampu LED bawah air dengan warna yang berbeda terhadap hasil tangkapan ikan teri (Stolephorus commersonii), serta mengetahui jumlah hasil tangkapan ikan teri (Stolephorus commersonii) pada bagan dengan menggunakan metode eksperimental, dimana data dianalisis dengan menggunakan Rancangan Acak Kelompok (RAK) dan dilanjutkan dengan uji Beda Nyata Terkecil (BNT). Uji coba penangkapan ikan teri (Stolephorus commersonii) dilakukan pada bulan Desember 2018 selama 10 hari dengan mengoperasikan bagan apung menggunakan lampu LED hijau, biru dan hijau-biru. Hasil penelitian menunjukkan bahwa penggunaan warna lampu LED dalam air biru memberikan pengaruh yang sangat nyata terhadap jumlah hasil tangkapan ikan teri (Stolephorus comersonii) dibandingkan warna lampu LED dalam air hijau-biru dan hijau. Sedangkan antara penggunaan warna lampu LED dalam air hijau-biru dengan hijau secara statistik tidak berbeda nyata terhadap jumlah hasil tangkapan ikan teri (Stolephorus comersonii).
\end{abstract}

Kata-kata kunci: Bagan apung; Warna lampu LED; Ikan teri (Stolephorus commersonii); Tateli Weru

\section{PENDAHULUAN}

Bagan adalah alat tangkap yang menggunakan cahaya sebagai alat bantu untuk menarik dan mengumpulkan ikan di daerah cakupan alat tangkap, sehingga memudahkan dalam proses penangkapan selanjutnya. Penggunaan cahaya lampu sebagai alat bantu penangkapan ikan sudah mulai dikenal sejak tahun 1950-an di Indonesia

\footnotetext{
*Penulis untuk penyuratan; email: yantiamos27@gmail.com
} 
yaitu awalnya dimulai dengan penggunaan obor, lampu gas karbit, lampu petromaks sampai penggunaan lampu listrik, dimana lampu listrik akan lebih efisien dan efektif sebab dapat ditempatkan baik pada permukaan perairan (surface water) maupun dalam air (under water lamp) dan menggunakan kapal-kapal yang relatif besar (Subani, 1983).

Penggunaan lampu dimanfaatkan sebagai alat bantu penangkapan ikan dengan maksud agar ikan terkonsentrasi pada suatu tempat, dimana alat penangkapan ikan dengan mudah dioperasikan. Salah satu cara yang umum digunakan oleh para nelayan dalam menarik, menggiring ikan serta mengumpulkan ikan adalah dengan menggunakan lampu (Katiandagho dan Kumajas, 1987).

Dalam operasinya bagan dilengkapi dengan jaring yang berbentuk kubus untuk membatasi gerak renang ikan kemudian diangkat agar ikan tidak dapat lolos lagi (Ayodhyoa, 1981).

Hasil tangkapan dari alat tangkap bagan umumnya terdiri atas jenis ikan yang berenang dekat permukaan perairan dan tertarik pada cahaya serta hidup bergerombol. Untuk itu, tujuan yang hendak dicapai dalam penelitian ini, adalah: 1). Mengetahui pengaruh warna lampu Light Emitting Diode (LED) dalam air terhadap hasil tangkapan pada bagan. 2). Mengetahui jumlah hasil tangkapan ikan teri (Stolephorus comersonii) yang tertangkap dengan menggunakan lampu Light Emitting Diode (LED) dalam air pada bagan.

\section{METODE PENELITIAN}

Penelitian ini dilaksanakan di perairan Tateli Weru, yang merupakan salah satu desa yang berada di Kecamatan Mandolang, Kabupaten Minahasa, Sulawesi Utara, Indonesia. Waktu Pelaksanaan penelitian berlangsung selama 4 bulan yaitu dari bulan November 2018 - Februari 2019.

Penelitian ini bersifat eksperimental yaitu suatu rancangan yang diuji cobakan untuk memperoleh informasi tentang persoalan yang sedang diteliti. Dengan metode ini dapat diperoleh informasi yang diperlukan dalam melakukan penelitian tentang pesoalan yang akan dibahas sehingga akan dihasilkan suatu kesimpulan sesuai dengan tujuan penelitian (Sudjana, 1994).

\section{Teknik Pengumpulan Data}

Teknik pengumpulan data dilakukan dengan cara pengamatan langsung dan tidak langsung.
Pengamatan langsung, yaitu teknik pengukuran, wawancara terhadap objek penelitian yang dijadikan sebagai data primer, sementara pengamatan tidak langsung terhadap objek penelitian, digunakan sebagai data sekunder.

Pada penelitian ini digunakan 3 unit bagan apung dengan 3 pasang lampu berwarna yang dioperasikan dalam air. Masing-masing unit bagan menggunakan sepasang lampu berwarna dengan kombinasi warna hijau-hijau (HH), biru-biru (BB), dan hijau-biru (HB). Penempatan setiap perlakuan dari pasangan lampu warna dalam air dilakukan secara acak, sehingga setiap perlakuan yang dibuat dianggap mempunyai peluang yang sama dalam menarik dan mengumpulkan ikan untuk berkumpul di area tangkap (catchable area) di mana "cang" atau jaring (webbing) berada.

Pengoperasian alat tangkap bagan apung dilakukan pada pukul $18.00-06.00$ wita. Setelah tiba di fishing ground, jaring mulai diturunkan ke dalam perairan. Selanjutnya lampu LED mulai dinyalakan dan diturunkan ke dalam perairan untuk memikat perhatian ikan agar berkumpul di bawah cahaya lampu. Ketika ikan telah berkumpul banyak di bawah cahaya lampu, lampu mulai dipindahkan ke tengah, dan kap merah diturunkan agar kelompok ikan yang telah berkumpul tidak menyebar. Setelah ikan berkumpul secara sempurna, maka jaring diangkat secara perlahanlahan dengan memutar roller. Pada saat jaring atau waring mendekati permukaan, jaring ditarik sedikit demi sedikit ke salah satu sisi bagan. Selanjutnya, ikan diangkat ke atas perahu dengan menggunakan serok.

\section{Analisis Data}

Data dalam penelitian ini dianalisis sesuai dengan desain Rancangan Kelompok Lengkap Teracak atau biasa juga disebut Rancangan Acak Kelompok (RAK) dengan model matematis dari rancangan tersebut sebagaimana dikemukakan oleh Steel dan Torrie (1989), sebagai berikut:

$Y_{i j}=\mu+\eta_{i}+\beta_{j}+\sum_{i j} \quad \ldots \ldots \ldots \ldots \ldots . . .$.

(i=1,2, ..., $\mathrm{t}$ (perlakuan); $\mathrm{j}=1,2, \ldots, \mathrm{r}$ (kelompok)

di mana:

$Y_{\mathrm{ij}}=$ Pengamatan dari perlakuan ke-i kelompok ke-j

$\mu=$ Rata-rata umum

$\eta_{\mathrm{i}}=$ Efek (pengaruh) perlakuan ke-i

$\beta_{\mathrm{j}}=$ Efek (pengaruh) kelompok ke-j 
$\sum_{\mathrm{ij}}=$ Efek unit eksperimen dalam kelompok ke-i karena perlakuan ke-j

Untuk memenuhi persyaratan analisis dalam menarik kesimpulan, maka dirumuskan hipotesis sebagai berikut:

$\mathrm{H}_{0}: \eta=0$, Berarti secara statistik tidak terdapat pengaruh dari perbedaan perlakuan warna lampu LED terhadap jumlah hasil tangkapan ikan teri (Stolephorus commersonii) pada bagan

$\mathrm{H} 1: \eta \neq 0$, Berarti secara statistik terdapat pengaruh dari perbedaan perlakuan warna lampu LED terhadap jumlah hasil tangkapan ikan teri (Stolephorus dimana, commersonii) pada bagan

a. Jika $F_{\text {hitung }} \leq \mathrm{F}_{\text {tabel, }}$, maka secara statistik Terima $\mathrm{H}_{0}\left(\right.$ Tolak $\left.\mathrm{H}_{1}\right)$, berarti tidak ada perbedaan atau pengaruh dari perlakuan warna lampu LED terhadap jumlah hasil tangkapan ikan teri (Stolephorus commersonii) pada bagan.

b. Jika $\mathrm{F}_{\text {hitung }}>\mathrm{F}_{\text {tabel, }}$, maka secara statistik Terima $\mathrm{H}_{1}$ (Tolak $\left.\mathrm{H}_{0}\right)$, berarti ada perbedaan atau pengaruh dari perlakuan warna lampu LED terhadap jumlah hasil tangkapan ikan teri (Stolephorus commersonii) pada bagan.

Nilai $F_{\text {tabel }}$ adalah nilai $F_{\alpha}\left(v_{1}, v_{2}\right)$ yang didapat dari daftar distribusi $\mathrm{F}$, di mana $\mathrm{v}_{1}$ adalah derajat bebas $(\mathrm{db})$ pembilang (dari perlakuan $)=\mathrm{t}-1$, dan $\mathrm{v}_{2}$ adalah derajat bebas penyebut $($ dari galat $)=(\mathrm{r}-1)(\mathrm{t}-1)$, dan $\alpha$ adalah taraf nyata sebesar $1 \%$. Jika $\mathrm{H}_{1}$ diterima maka perlu dilakukan uji lanjut untuk mengetahui perlakuan mana yang berbeda dengan menggunakan uji "Uji Beda Nyata Terkecil" (BNT) sebagaimana dikemukakan dalam Sudjana (1980) dengan menggunakan formulasi perhitungan sebagai berikut:

$\operatorname{BNT}(1 \%)=\mathrm{t}(\mathrm{db}$ galat, $1 \%) \times \sqrt{\frac{2 K T G}{r}} \ldots$

dimana:

BNT $(1 \%)=$ Beda nyata terkecil pada tingkat kepercayaan $1 \%$

$\mathrm{t}(\mathrm{db}$ galat, $1 \%)=$ Nilai $\mathrm{t}$ tabel

KTG $=$ Kuadrat Tengah Galat

$\mathrm{r}=$ Jumlah ulangan/kelompok

\section{HASIL DAN PEMBAHASAN}

Ikan teri (Stolephorus commersonii) adalah hasil tangkapan yang menjadi tujuan utama pada pengoperasian alat tangkap bagan, dan merupakan ikan pelagis kecil yang bersifat fototaksis positif, yaitu ikan yang tertarik oleh cahaya. Jumlah berat hasil tangkapan yang diperoleh dalam penelitian ini tertera pada tabel 1 .

Jumlah berat hasil tangkapan ikan teri (Stolephorus commersonii) dari ketiga bagan yang digunakan dalam penelitian ini berdasarkan penggunaan sumber cahaya dari tiga set lampu berwarna selama 10 hari pengamatan, diperlihatkan pada tabel 1 dan Gambar 1

Tabel 1. Hasil tangkapan ikan teri (Stolephorus commersonii) dari tiga unit bagan dengan menggunakan tiga pasang lampu LED dalam air

\begin{tabular}{|c|c|c|c|c|c|c|}
\hline \multirow[b]{2}{*}{$\begin{array}{l}\text { Operasi } \\
\text { Penangkapan }\end{array}$} & \multicolumn{2}{|c|}{ Bagan 1} & \multicolumn{2}{|c|}{ Bagan 2} & \multicolumn{2}{|c|}{ Bagan 3} \\
\hline & Warna & $\begin{array}{l}\text { Hasil } \\
\text { Tangkapan } \\
\text { (kg) }\end{array}$ & Warna & $\begin{array}{l}\text { Hasil } \\
\text { Tangkapan } \\
(\mathrm{kg})\end{array}$ & Warna & $\begin{array}{l}\text { Hasil } \\
\text { Tangkapan } \\
(\mathrm{kg})\end{array}$ \\
\hline 1 & $\mathrm{HH}$ & $440 \mathrm{~kg}$ & BB & $280 \mathrm{~kg}$ & $\mathrm{HB}$ & $180 \mathrm{~kg}$ \\
\hline 2 & $\mathrm{BB}$ & $560 \mathrm{~kg}$ & HB & $400 \mathrm{~kg}$ & $\mathrm{HH}$ & $360 \mathrm{~kg}$ \\
\hline 3 & $\mathrm{HB}$ & $120 \mathrm{~kg}$ & $\mathrm{HH}$ & $520 \mathrm{~kg}$ & BB & $660 \mathrm{~kg}$ \\
\hline 4 & $\mathrm{HH}$ & $240 \mathrm{~kg}$ & $\mathrm{BB}$ & $560 \mathrm{~kg}$ & $\mathrm{HB}$ & $320 \mathrm{~kg}$ \\
\hline 5 & $\mathrm{BB}$ & $480 \mathrm{~kg}$ & $\mathrm{HB}$ & $220 \mathrm{~kg}$ & $\mathrm{HH}$ & $60 \mathrm{~kg}$ \\
\hline 6 & $\mathrm{HB}$ & $300 \mathrm{~kg}$ & $\mathrm{HH}$ & $180 \mathrm{~kg}$ & $\mathrm{BB}$ & $360 \mathrm{~kg}$ \\
\hline 7 & $\mathrm{HH}$ & $160 \mathrm{~kg}$ & BB & $440 \mathrm{~kg}$ & $\mathrm{HB}$ & $220 \mathrm{~kg}$ \\
\hline 8 & $\mathrm{BB}$ & $660 \mathrm{~kg}$ & $\mathrm{HB}$ & $520 \mathrm{~kg}$ & $\mathrm{HH}$ & $240 \mathrm{~kg}$ \\
\hline 9 & $\mathrm{HB}$ & $520 \mathrm{~kg}$ & $\mathrm{HH}$ & $340 \mathrm{~kg}$ & $\mathrm{BB}$ & $440 \mathrm{~kg}$ \\
\hline 10 & $\mathrm{HH}$ & $280 \mathrm{~kg}$ & $\mathrm{BB}$ & $540 \mathrm{~kg}$ & $\mathrm{HB}$ & $360 \mathrm{~kg}$ \\
\hline Hasil Tangkapan & & $3760 \mathrm{~kg}$ & & $4000 \mathrm{~kg}$ & & $3200 \mathrm{~kg}$ \\
\hline
\end{tabular}

Keterangan: $\mathrm{HH}=$ Hijau-Hijau; $\mathrm{BB}=$ Biru-Biru; $\mathrm{HB}=$ Hijau-Biru 

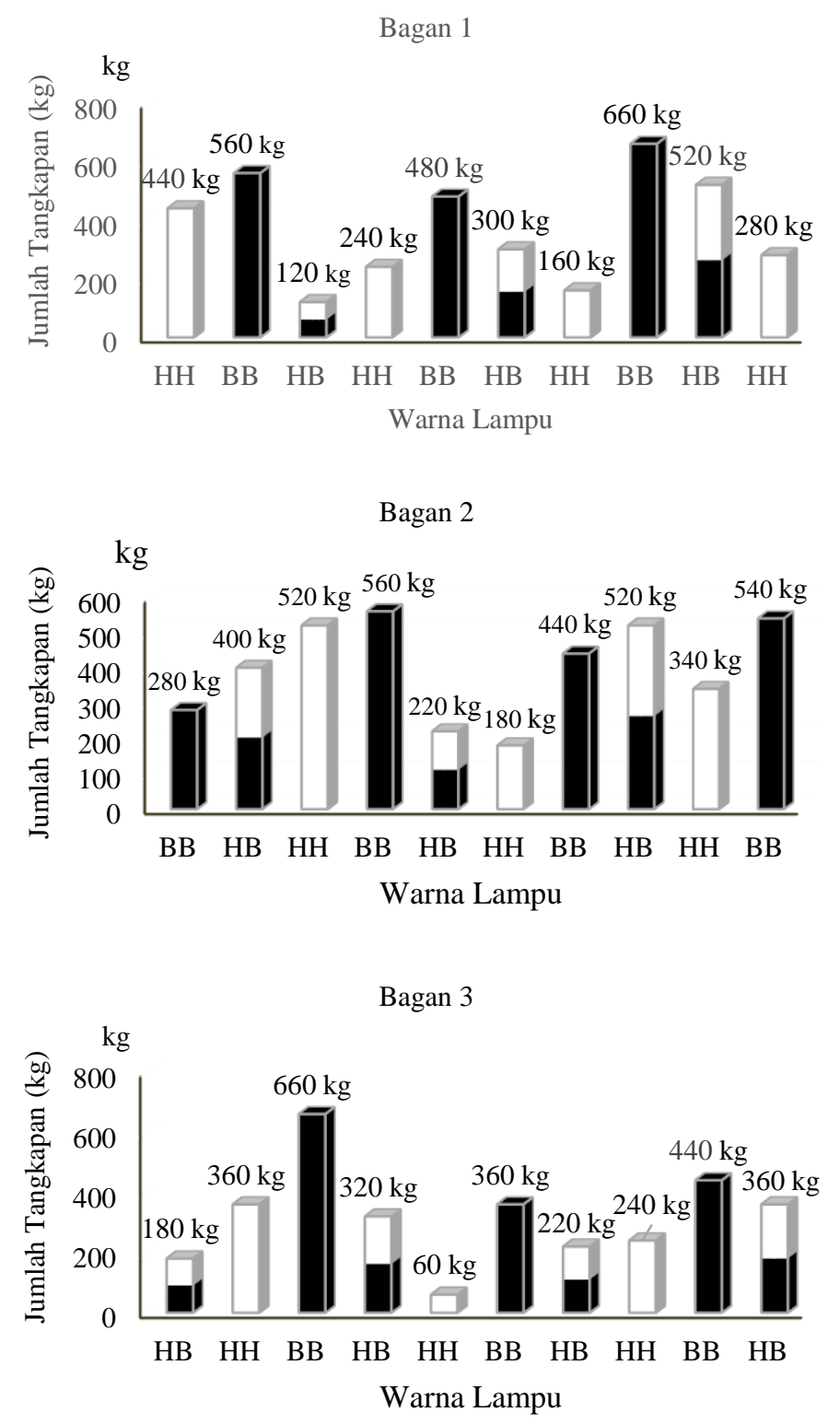

Gambar 1. Hasil tangkapan ikan teri (Stolephorus commersonii) dari tiga unit bagan apung dengan menggunakan tiga pasang lampu LED dalam air

Hasil tangkapan berdasarkan perlakuan warna lampu LED dalam air menunjukkan bahwa jumlah ikan teri (Stolephorus commersonii) yang tertangkap pada bagan apung dengan warna lampu biru-biru (BB) relatif lebih banyak bila dibandingkan lampu warna lampu hijau-biru (HB) dan hijau-hijau (HH).

Hasil analisis sidik ragam (Tabel 3) menunjukkan bahwa kelompok (hari) tidak menunjukkan pengaruh yang nyata (signifikan) terhadap hasil tangkapan ikan pada perikanan bagan. Sebaliknya, penggunaan warna lampu LED dalam air sebagai perlakuan ternyata pengaruhnya sangat nyata terhadap jumlah berat hasil tangkapan pada perikanan bagan yang dioperasikan selama 10 hari.yang dioperasikan selama 10 hari. 
Tabel 2. Berat hasil tangkapan (kg) bagan apung menurut warna lampu LED dalam air

\begin{tabular}{lllll}
\hline \multirow{2}{*}{ Kelompok } & \multicolumn{4}{c}{ Warna Lampu } \\
\cline { 2 - 4 } & $\mathrm{HH}$ & $\mathrm{BB}$ & $\mathrm{HB}$ & Total \\
\hline 1 & $440 \mathrm{~kg}$ & $280 \mathrm{~kg}$ & $180 \mathrm{~kg}$ & $900 \mathrm{~kg}$ \\
2 & $360 \mathrm{~kg}$ & $560 \mathrm{~kg}$ & $400 \mathrm{~kg}$ & $1320 \mathrm{~kg}$ \\
3 & $520 \mathrm{~kg}$ & $660 \mathrm{~kg}$ & $120 \mathrm{~kg}$ & $1300 \mathrm{~kg}$ \\
4 & $240 \mathrm{~kg}$ & $560 \mathrm{~kg}$ & $320 \mathrm{~kg}$ & $1120 \mathrm{~kg}$ \\
5 & $60 \mathrm{~kg}$ & $480 \mathrm{~kg}$ & $220 \mathrm{~kg}$ & $760 \mathrm{~kg}$ \\
6 & $180 \mathrm{~kg}$ & $360 \mathrm{~kg}$ & $300 \mathrm{~kg}$ & $840 \mathrm{~kg}$ \\
7 & $160 \mathrm{~kg}$ & $440 \mathrm{~kg}$ & $220 \mathrm{~kg}$ & $820 \mathrm{~kg}$ \\
8 & $240 \mathrm{~kg}$ & $660 \mathrm{~kg}$ & $520 \mathrm{~kg}$ & $1420 \mathrm{~kg}$ \\
9 & $340 \mathrm{~kg}$ & $440 \mathrm{~kg}$ & $520 \mathrm{~kg}$ & $1300 \mathrm{~kg}$ \\
10 & $280 \mathrm{~kg}$ & $540 \mathrm{~kg}$ & $360 \mathrm{~kg}$ & $1180 \mathrm{~kg}$ \\
Jumlah & $2820 \mathrm{~kg}$ & $4980 \mathrm{~kg}$ & $3160 \mathrm{~kg}$ & $10960 \mathrm{~kg}$ \\
\hline
\end{tabular}

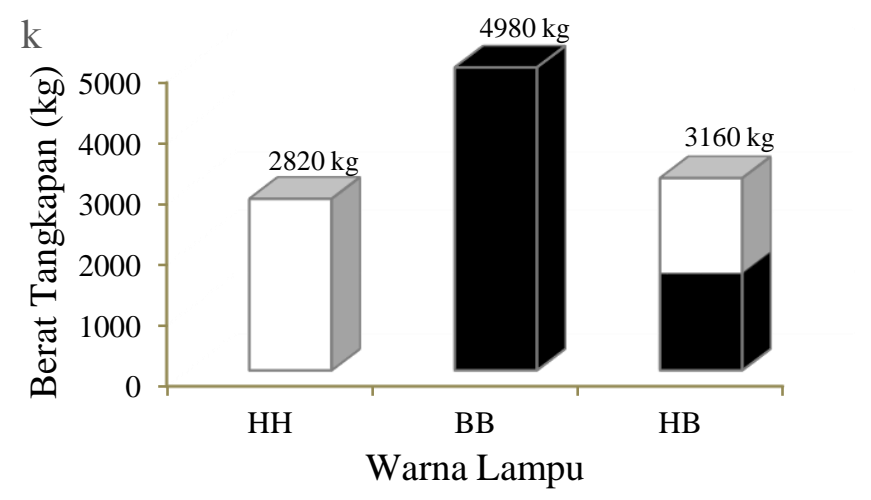

Gambar 2. Perbedaan jumlah hasil tangkapan ikan teri (Stolephorus commersonii) pada bagan apung antara perlakuan yang satu dengan perlakuan lainnya

Tabel 3. Analisis sidik ragam hasil tangkapan bagan apung

\begin{tabular}{llllll}
\hline Sumber Keragaman & Db & JK & KT & F hitung & F tabel 1\% \\
\hline Kelompok & 9 & 179680 & 19964.44 & $1,23^{\text {tn }}$ & 3.6 \\
Perlakuan & 2 & 269786.7 & 134893.3 & $8,29^{* *}$ & 6.01 \\
Galat & 18 & 292880 & 16271.11 & & \\
Total & 29 & 742346.7 & & & \\
\hline
\end{tabular}

Keterangan: $* *=$ sangat nyata; $\mathrm{tn}=$ tidak nyata

Perbedaan hari operasi penangkapan tidak menunjukkan pengaruh yang nyata terhadap hasil tangkapan, mungkin berkaitan dengan kondisi lingkungan perairan pada saat penelitian berlangsung yang relatif sama. Kondisi perairan pada saat pengoperasian bagan memiliki arus yang relatif tenang, gelombang juga relatif kecil. Namun, cuaca selama penelitian berlangsung agak berawan. Menurut Sukandar dan Fuad (2015) kondisi cuaca sangat berpengaruh terhadap keberhasilan operasi penangkapan ikan.

Untuk mengetahui perlakuan mana yang paling berpengaruh, maka dilanjutkan dengan uji Beda Nyata Terkecil (Tabel 4).

Hasil uji lanjut dengan menggunakan BNT (Tabel 4) terhadap rata-rata hasil tangkapan ikan teri antara tiga perlakuan pada 10 hari pengamatan, menunjukkan bahwa penggunaan warna lampu LED dalam air biru-biru (BB) memberikan 
pengaruh yang sangat nyata terhadap jumlah hasil tangkapan ikan teri (Stolephorus commersonii) dibandingkan warna lampu hijau-biru (HB) dan hijau-hijau (HH). Sedangkan hasil tangkapan ikan teri (Stolephorus commersonii) tidak berbeda nyata secara statistik antara penggunaan warna lampu LED hijau-biru (HB) dengan hijau-hijau (HH).

Rata-rata hasil tangkapan secara keseluruhan pada 10 hari pengamatan pada penggunaan lampu LED dalam air warna biru-biru (BB) adalah $498 \mathrm{~kg}$, warna hijau-biru (HB) $316 \mathrm{~kg}$, dan warna hijauhijau (HH) $282 \mathrm{~kg}$. Menurut Sudirman dan Mallawa (2004) dalam Urbasa $d k k$, (2015) menyatakan bahwa kemampuan ikan untuk tertarik pada suatu sumber cahaya sangat berbeda-beda, hal ini di karenakan jenis ikan memiliki ketertarikan yang berbeda terhadap warna.

Tingginya hasil tangkapan pada warna lampu LED dalam air biru-biru (BB) mungkin berkaitan dengan panjang gelombang dan penetrasinya ke dalam air. Semakin besar panjang gelombangnya maka semakin kecil daya tembusnya masuk ke dalam perairan, begitupun sebaliknya.
Menurut Notanubun dan Patty (2010) cahaya lampu LED warna biru memiliki panjang gelombang yang pendek dan spektrum cahayanya lebih panjang, sehingga intensitasnya lebih tinggi serta warna biru lebih banyak disukai oleh banyak jenis ikan.

Cahaya warna biru memiliki panjang gelombang 455-492 nm dengan frekuensi spektrum cahayanya adalah $610-659 \mathrm{~Hz}$, sedangkan cahaya warna hijau memiliki panjang gelombang 492-577 nm dengan spektrum cahayanya adalah $520-610 \mathrm{~Hz}$ (Arkundato, 2008).

Cahaya warna biru memiliki panjang gelombang yang rendah sehingga jangkauannya sangat jauh di dalam perairan. Cahaya ini mampu menarik ikan-ikan pelagis kecil dan ikan-ikan demersal. Hal ini memungkinkan peluang yang lebih besar untuk ikan-ikan pada lokasi yang lebih jauh untuk merespons cahaya lampu untuk tertarik dan berkumpul pada cacthable area bagan. Faktor berkumpulnya ikan pada catchable area dapat disebabkan salah satunya karena pengaruh cahaya (Sudirman dan Mallawa. 2004; Purbayanto $d k k$, 2010; Simbolon $d k k, 2010)$.

Tabel 4. Uji Beda Nyata Terkecil (BNT) untuk perlakuan

\begin{tabular}{lllll}
\hline Perlakuan Warna lampu & N. Tengah & Selisih & Nilai & Signifikansi \\
\hline Biru-Biru (BB) & 498 & BB-HB & 182 & $* *$ \\
Hijau-Biru (HB) & 316 & BB-HH & 216 & $* *$ \\
Hijau-Hijau (HH) & 282 & HB-HH & 34 & tn \\
\hline
\end{tabular}

Keterangan: $* *=$ sangat nyata $; \mathrm{tn}=$ tidak nyata

BB $\quad \mathrm{HB} \quad \mathrm{HH}$

\section{KESIMPULAN}

Dari hasil penelitian dapat disimpulkan bahwa penggunaan lampu LED dalam air pada bagan sangat berpengaruh terhadap hasil tangkapan. Sedangkan waktu operasi penangkapan tidak menunjukkan pengaruh yang nyata terhadap hasil tangkapan ikan teri (Stolephorus commersonii). Lampu LED dalam air berwarna biru-biru (BB) memberikan hasil tangkapan yang lebih banyak dibandingkan lampu LED berwarna hijau-biru (HB) dan hijau-hijau (HH). Jumlah hasil tangkapan ikan teri (Stolephorus comersonii) berdasarkan perlakuan warna lampu biru-biru (BB) adalah 498 $\mathrm{kg}$, hijau-biru (HB) $316 \mathrm{~kg}$, dan hijau-hijau (HH) $282 \mathrm{~kg}$.

\section{UCAPAN TERIMA KASIH}

Ucapan terima kasih disampaikan kepada bpk. Mita Rungkulalo sebagai pemilik bagan yang telah memberikan fasilitas untuk penelitian. Dan juga bpk. Eklis dan nelayan lainnya yang telah membantu dilapangan selama penelitian.

\section{DAFTAR PUSTAKA}

Arkundato, A. 2008. Produksi Cahaya. [Online]. Melalui <http://repository.ut.ac.id/4459/2/PEFI4311-M1.pdf> [11/6/2019].

Ayodhyoa, A.U. 1981. Metode Penangkapan Ikan. Bogor (ID): Yayasan Dewi Sri. Bogor. 81 hal. 
Katiandagho, E.M., dan Kumajas, H.J. 1987. Metode Penangkapan Ikan. Fakultas Perikanan Universitas Sam Ratulangi, Manado. 145 hal.

Notanubun, J., dan Patty, W. 2010. Perbedaan Penggunaan Intensitas Cahaya Lampu Terhadap Hasil Tangkapan Bagan Apung Di Perairan Selat Rosenberg Kabupaten Maluku Tenggara Kepulauan Kei. Jurnal Perikanan dan Kelautan. 6(3): 134-140.

Purbayanto, A., Riyanto M., Fitri A.D.P. 2010. Fisiologi dan Tingkah Laku Ikan pada Perikanan Tangkap. Bogor (ID): IPB Press.

Simbolon D, Sondita MFA, Amiruddin. 2010. Komposisi isi saluran pencernaan ikan teri (Stolephorus spp) di Perairan Barru, Selat Makassar. J Marine Indones Sci. 15(1):7-16.

Subani, W. 1983. Penggunaan Lampu Sebagai Alat Bantu Penangkapan Ikan. Laporan Penelitian Perikanan Laut. 27:45-48.
Sudirman dan Mallawa. 2004. Teknik Penangkapan Ikan. Rineka Cipta, Jakarta

Sudjana. 1980. Metoda Statistika. Badung: Tarsito.

Sudjana. 1994. Disain dan Analisis Eksperimen. Edisi II, Tarsito, Band

Sukandar dan Fuad. 2015. Pengoperasian Lampu Celup Bawah Air pada Bagan Tancap di Perairan Lekok. Journal of Innovation and Applied Technology. 1(2): 101-105.

Urbasa, F, F. E. Kaparang, dan H. J. Kumajas. 2015. Studi Ketertarikan Ikan di Keramba Jaring Apung Terhadap Warna Cahaya Lampu di Perairan Sindulang I, Kecamatan Tuminting, Kota Manado. Jurnal Ilmu dan Teknologi Perikanan Tangkap. 2(Edisi Khusus): 39-43. E-Journal online.Melalui<https://ejournal.unsrat.ac.id/index.php/JITPT /article/view/7020/6883> [19/5/2019]. 